\title{
A EFICIÊNCIA ENERGÉTICA DA PASSIVHAUS APLICADA A CLIMAS TROPICAIS
}

\author{
Elder Franklin da Silva ${ }^{1}$ \\ Ellen Melo Ribeiro de Sousa ${ }^{2}$ \\ Gabriela Cristina de Abreu Gouveia Castro ${ }^{3}$ \\ Giovanni Dias de Faria ${ }^{4}$ \\ Natacha Froes de Oliveira ${ }^{5}$ \\ Luiz Gustavo Paulo Oran Barros ${ }^{6}$
}

Resumo: As fontes de energia elétrica convencionais vêm sofrendo grandes críticas acerca de responsabilidade ambiental e eficiência. Existe uma necessidade de encontrarmos meios mais limpos e eficientes de produção energética e também equipamentos que consumam menos, ou que não necessitam de energia elétrica e garantam funcionalidade e conforto. A passivhaus é um padrão de arquitetura que busca a eficiência de uma residência passiva de energia elétrica convencional, pensando nos conceitos de conforto térmico, acústico, iluminação natural, aquecimento de água e ventilação que precisam de pouca ou nenhuma eletricidade para funcionar. Para a aplicação do padrão em climas tropicais, é necessário que sejam feitas algumas modificações, já que o estudo original foi desenvolvido para climas frios do Hemisfério Norte.

Palavras-chave: Passivhaus; Arquitetura; Eficiência Energética.

\footnotetext{
1 Arquitetura e Urbanismo/Universidade do Vale do Paraíba, Brasil. E-mail: elderfranssa@gmail.com.

2 Arquitetura e Urbanismo/Universidade do Vale do Paraíba, Brasil. E-mail: ellenmelsousa10@gmail.com.

${ }^{3}$ Arquitetura e Urbanismo/Universidade do Vale do Paraíba, Brasil. E-mail: gabrielagouveia@live.com.

${ }^{4}$ Arquitetura e Urbanismo/Universidade do Vale do Paraíba, Brasil. E-mail: diasgiovanni.f@gmail.com.

5 Arquitetura e Urbanismo/Universidade do Vale do Paraíba, Brasil. E-mail: natachafroes@gmail.com.

${ }^{6}$ Arquitetura e Urbanismo/Universidade do Vale do Paraíba, Brasil. E-mail: oran@univap.br.
} 